\title{
Polyphenol-rich blackcurrant and apple extracts inhibit glucose uptake in in vitro models of intestinal sugar transport, but individual anthocyanins have no effect
}

\author{
M.L. Castro-Acosta, W.L. Hall and C.P. Corpe \\ Diabetes \& Nutritional Sciences Division, King's College London, Franklin-Wilkins Building, 150 Stamford Street, \\ London, SE1 9NH, UK
}

Consumption of foods with high content of polyphenols has been associated with reduced risk for type 2 diabetes, and randomised controlled trials have shown inhibition of postprandial glycaemia. Mechanisms proposed include blocking of intestinal glucose transporters (e.g. SGLT1, GLUT2) ${ }^{1-3}$. In previous clinical trials, our group has shown an anthocyanin-rich blackcurrant extract (BE) and a proanthocyanidin- and chlorogenic acid-rich apple extract (AE) inhibit postprandial glycaemia (unpublished data). The aim of the present project is to identify the mechanisms of postprandial glycaemia inhibition by $\mathrm{BE}, \mathrm{AE}$ and $\mathrm{BE}$ individual compounds on intestinal sugar transport using Caco-2/TC-7 cells and Xenopus oocytes injected to express SGLT1. For intestinal cell experiments, Caco-2 cells were cultured in 24-well plates and grown for 2-3 weeks. For Xenopus oocytes experiments, oocytes were injected with cRNA encoding SGLT1 and used 3-4 days post injection. Carrier mediated sugar transport and the effects of BE, AE and BE individual compounds (delphinidin-3-rutinoside, delphinidin-3-glucoside, delphinidin, cyanidin-3-rutinoside, cyanindin-3glucoside and cyanidin) were studied by dose response assays. D-glucose (10 mM) was used alongside radioactive sugar Glucose, $\mathrm{D}-[14 \mathrm{C}(\mathrm{U})]$ as tracer. The range of concentrations applied to cells in uptake media (10 min uptake) was kept at physiological levels; BE $0.075-2.4 \mathrm{mM}$ total anthocyanins, AE $0.05-1.5 \mathrm{mg}$ polyphenols $/ \mathrm{ml}$ and BE individual anthocyanins $0 \cdot 1-0.6 \mathrm{mM}$. Nonlinear regression analysis was used to estimate $\mathrm{IC}_{50} \mathrm{~s}$ (GraphPad Prism) and one-way ANOVA for comparisons between treatments (SPSS v.21). The presence of different concentrations of BE and AE in the uptake media significantly reduced total ( $\mathrm{Na}^{+}$-containing buffer, SGLT1- and GLUTs-mediated), facilitated $\left(\mathrm{Na}^{+}\right.$-free buffer, GLUTs-mediated) and SGLT1-mediated (oocytes expressing SGLT1 only) glucose transport into cells in a dose-response manner $(P<0.05)$. Values for $\mathrm{IC}_{50} \mathrm{~s}$ of $\mathrm{BE}$ and $\mathrm{AE}$ are shown in the table; results suggest a greater inhibition of total compared with only facilitated glucose uptake. At a dose equivalent to 1 portion of blackcurrants ( $80 \mathrm{~g}, 0.48 \mathrm{mM}$ anthocyanins) and apple $(80 \mathrm{~g}, 0.1 \mathrm{mg} / \mathrm{ml})$, inhibition of facilitated (GLUTs-mediated) uptake accounted for 40 and $\sim 20 \%$ of total inhibition of glucose uptake respectively. BE individual compounds did not inhibit glucose uptake.

\begin{tabular}{|c|c|c|c|c|}
\hline \multirow[b]{2}{*}{ In vitro models of glucose uptake } & \multicolumn{2}{|c|}{$\mathrm{IC}_{50}$ Blackcurrant extract $(\mathrm{mM})$} & \multicolumn{2}{|c|}{$\mathrm{IC}_{50}$ Apple extract $(\mathrm{mg} / \mathrm{ml})$} \\
\hline & Total uptake & Facilitated uptake & Total uptake & Facilitated uptake \\
\hline Caco-2 cells & $0 \cdot 32$ & $0 \cdot 56$ & $0 \cdot 09$ & $0 \cdot 24$ \\
\hline Oocytes expressing SGLT1 only & $0 \cdot 11$ & & 0.05 & \\
\hline
\end{tabular}

In conclusion, these in vitro experiments suggest that the acute inhibitory effect of BE and AE on postprandial glycaemia observed in our clinical studies is likely to be at least partly due to inhibition of SGLT1 and GLUTs, but further investigation is required as to whether individual anthocyanins act predominantly via other routes such as inhibition of digestive enzymes.

1. Williamson G (2013) Mol Nutr Food Res 57, 48-57

2. Johnston K, Sharp P., Clifford M et al. (2005) FEBS Lett 579, 1653-1657

3. Kwon E, Eck P, Chen S et al. (2007) FASEB J 21, 366-377 